\title{
Rationale for aortic annuloplasty to standardise aortic valve repair
}

\author{
Pouya Youssefi ${ }^{1}$, Ismail El-Hamamsy ${ }^{2}$, Emmanuel Lansac $^{1}$ \\ ${ }^{1}$ Department of Cardiac Surgery, Institut Mutualiste Montsouris, Paris, France; ${ }^{2}$ Division of Cardiac Surgery, Montreal Heart Institute, Universite \\ de Montreal, Montreal, Quebec, Canada \\ Correspondence to: Emmanuel Lansac, MD, PhD. Department of Cardiac Surgery, Institut Mutualiste Montsouris, Paris, France. \\ Email: emmanuel.lansac@imm.fr.
}

\begin{abstract}
Available evidence shows that aortic valve repair reduces valve-related mortality and improves quality of life compared to prosthetic aortic valve replacement. One of the most important predictors of bicuspid and tricuspid aortic valve repair failure is the absence of treating a dilated aortic annulus greater than 25$28 \mathrm{~mm}$. Competency of the aortic valve depends on multiple factors including the diameter of the annulus, sinotubular junction, valve cusps and commissures. Dystrophic aortic insufficiency (AI) is the commonest cause of $\mathrm{AI}$ in the Western world and is characterised by dilatation of the aortic annulus ( $\geq 25 \mathrm{~mm}$ ), sinuses and/or sinotubular junction $(\geq 30 \mathrm{~mm})$. Depending on whether the sinuses of Valsalva and/or tubular ascending aorta are dilated, three phenotypes can be identified: dilated aortic root, dilated ascending aorta and isolated AI. All three phenotypes are associated with a dilated aortic annulus. Aortic annuloplasty reduces the dilated aortic annulus and improves the surface of coaptation, as in the case of mitral valve repair. In treating AI, it is also important to restore the physiological sinotubular junction/annulus ratio, which can be carried out with remodeling root repair + subvalvular annuloplasty (for dilated aortic root), tubular ascending aorta replacement + subvalvular annuloplasty (for dilated ascending aorta) and double sub- and supra-valvular annuloplasty (for isolated AI). Aortic annuloplasty is now considered an essential component of aortic valve repair and valve-sparing root surgery.
\end{abstract}

Keywords: Aortic insufficiency (AI); repair; annuloplasty ring; remodeling; root replacement

Submitted Apr 29, 2019. Accepted for publication May 03, 2019.

doi: 10.21037 /acs.2019.05.13

View this article at: http://dx.doi.org/10.21037/acs.2019.05.13

\section{Introduction}

The recent 2017 European Association for Cardio-Thoracic Surgeons (EACTS)/European Society of Cardiology (ESC) guidelines for valvular heart disease recommendation for management of aortic root aneurysm (originally called annulo-aortic ectasia) is to use "reimplantation or remodeling with aortic annuloplasty" for valve-sparing root replacement, referring to the need of addressing the annulus (1). Indeed, a dilated aortic annulus greater than $25-28 \mathrm{~mm}$, if left untreated, is clearly documented as a major risk factor for failure of bicuspid and tricuspid aortic valve (AV) repair procedures $(2,3)$. Aortic annuloplasty efficiently addresses this issue, aiming at a sustained long-term outcome by reducing the dilated aortic annulus and improving the surface of coaptation, as in the case of mitral valve repair.
As a result, aortic annuloplasty is now considered as an essential component of $\mathrm{AV}$ repair and valve-sparing root surgery (VSRR). This review describes the anatomical landmarks and available techniques for aortic annuloplasty. as well as a standardised approach to AV repair with ring annuloplasty according to each aorta phenotype.

\section{Dystrophic aortic insufficiency (AI): a diameter disease}

According to the Euro Heart Survey on Valvular Heart Disease, dystrophic AI represents the most common etiology of aortic insufficiency (AI) in western countries, accounting for approximately two-thirds of all cases $(50 \%$ degenerative, $15 \%$ congenital) (4). These represent good candidates for AV repair. Dystrophic AI is characterized by 
Standardised approach of aortic valve repair according to aorta phenotype
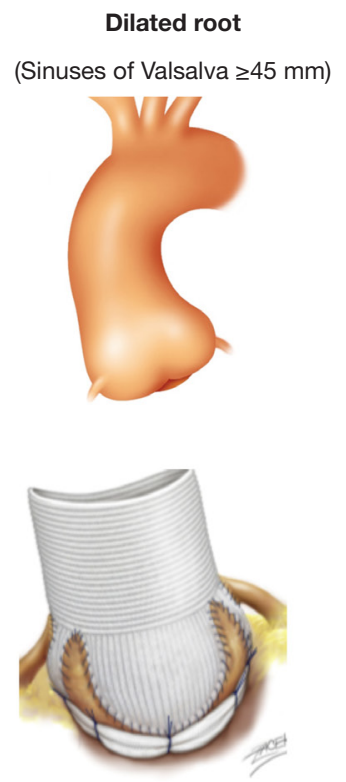

Remodeling \& Annuloplasty
Dilated ascending aorta

Asc aorta $\geq 45 \mathrm{~mm}$ (with normal root $\leq 40-45 \mathrm{~mm}$ )
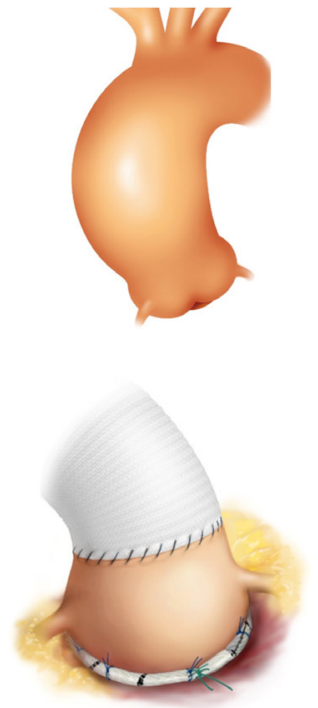

Asc aorta replacement \& annuloplasty
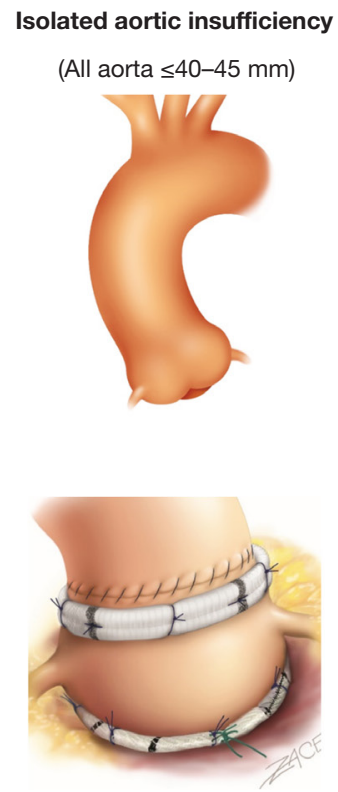

Double sub- + supravalvular annuloplasty

Figure 1 Algorithm of management of the aorta in aortic valve repair for aortic insufficiency. Drawing by Pavel Zacek (used with kind permission).

dilatation of the aortic annulus, sinuses and/or sinotubular junction (STJ) diameters preventing coaptation of pliable leaflets which may also be subjected to prolapse. Depending on whether the sinuses of Valsalva and/or the tubular ascending aorta are dilated, three phenotypes can be individualized: the first phenotype is normal root and ascending aorta (all diameters $\leq 40-45 \mathrm{~mm}$ ); the second is dilatation of the aortic root (sinus of Valsalva $\geq 45 \mathrm{~mm}$ ) and the third is dilatation of the ascending aorta $(\geq 45 \mathrm{~mm})$ (Figure 1). Dilatation of the annulus and STJ are almost constantly associated with any of these aorta phenotypes as a combined mechanism of AI.

Although patients with dystrophic AI are good candidates for repair, only $1.7 \%$ of AI patients have their valve spared. The Society of Thoracic Surgeons' database analysis showed a slight improvement with $14 \%$ of patients who underwent aortic root surgery receiving a valve sparing procedure (20\% of low risk and $6 \%$ of high risk patients), but still leaving $80 \%$ of root procedures for $\mathrm{AI}$ and/or root aneurysm as composite valve and graft replacement (Bentall procedure) $(5,6)$. In order to increase the rate of valve repair, the latest 2017 EACTS/ESC guidelines for heart valve disease recommend a "beart team discussion" for selected patients "with pliable, non-calcified" AV insufficiency "in whom aortic valve repair may be a feasible alternative to valve replacement" (class IC indication) (1). Standardization of AV repair techniques and their teaching will be key for the dissemination of repair uptake amongst surgeons, with development of high-volume centers of expertise being imperative for improved long-term patient outcomes.

\section{Anatomical landmarks for aortic annuloplasty}

The aortic annulus has been described in different ways, with terms such as virtual ring, basal ring, or ventriculoaortic junction (7-12). However, the term "annulus" is a consensus terminology to define the inflow of the aortic root as the plane passing through the nadir of the aortic cusps that can be measured either on echo long axis view or by direct intubation intra operatively. It also avoids confusion with "ring" repair prostheses.

Large pooled echocardiographic studies have shown that the mean STJ [27.2 mm (range, 24.7-29.5 mm)] is larger than the aortic annulus [22.3 mm (range, 20.5-24.5 mm)] 


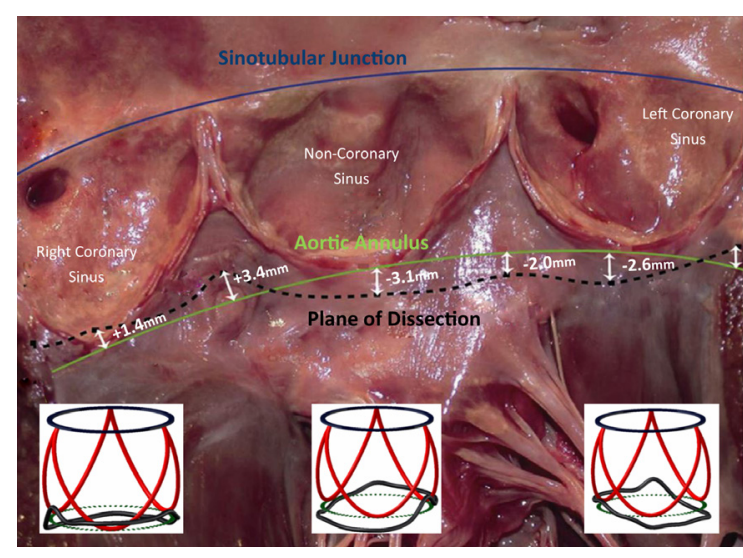

Figure 2 The aortic root opened with the cusps removed. The blue line indicates the sinotubular junction. The green line indicates the aortic annulus. The dotted line shows the subvalvular dissection plane. The schematic 3-dimensional aortic annular views at the bottom show the cusp insertion points (red line), plane of dissection (thick black line) and the aortic annulus (dotted line) viewed from each sinus.

diameter with a STJ/aortic annular base ratio of $1.2(13,14)$. Therefore, an aortic annulus diameter larger than $25 \mathrm{~mm}$ and a STJ diameter larger than $30 \mathrm{~mm}$ are deemed as functionally dilated. The importance of root geometry on valve competence has been demonstrated by a number of finite element studies. Marom et al. showed that reduction of STJ induces a symmetrical prolapse by lowering the effective height $(\mathrm{eH})$ of the cusp while dilation of aortic annulus diameter reduces mostly the coaptation height (cH) (15). As a result, an annuloplasty will essentially increase the $\mathrm{cH}$ with almost no effect on $\mathrm{eH}$. The systolic expansibility of the aortic root distributes dynamic stress to be lower during opening and closure of the $\mathrm{AV}$ and is documented to be around $6.2 \%$ and $5.7 \%$ at the aortic annulus and STJ levels, respectively $(13,16)$.

External dissection down to the subvalvular plane is very important in external ring annuloplasty or reimplantation root procedures. On tricuspid AVs with normal sized aortic roots, external dissection of the annulus may be achieved down to the subvalvular level below the nadir of the left and the non-coronary cusps (basal ring) and in $80 \%$ of cases below or within $3 \mathrm{~mm}$ of the nadir of the right cusp (7,17-21). Of importance to the surgical technique of dissecting down to the subvalvular level, it is difficult to fully reach down to the subvalvular plane in the region below the right-non commissure.
Here, the membranous septum limits the dissection plane and the base of the right-non interleaflet triangle corresponds externally to the insertion of the membranous septum, right atrium wall, infundibulum and septal leaflet of the tricuspid valve (18). Therefore, by dissecting down to this deepest plane, the external annuloplasty ring or the proximal suture line of the reimplantation tube graft would fully match the subvalvular plane below at least the left and non-coronary cusps and remain below or within $3 \mathrm{~mm}$ of the nadir of the right coronary cusp $80 \%$ of the time (Figure 2). The muscular part of the annulus is its thickest portion (with a mean thickness of $2.5 \mathrm{~mm}$ ). Therefore, an external annuloplasty would produce a reduction in the annulus of at least $5 \mathrm{~mm}(8,22)$.

\section{Valve-sparing aortic root replacement- addressing the annulus}

Two operations have been described to replace the aortic root whilst preserving the native AV. Yacoub described the remodeling technique whereby a tube graft is modified to create three scallops or neo-sinuses which are sutured to the aortic wall directly adjacent to the cusp insertion points (23). This allows the root to expand during systole through the interleaflet triangles. David described the reimplantation technique where the $\mathrm{AV}$ is contained within a tube graft (David I technique) (24). Both techniques treat the dilation of the STJ by bringing the commissure to the diameter of the tube. However, whereas the remodeling technique has the advantage of preserving the geometry of the three sinuses of Valsalva and its resultant vortical flow (25), as well as maintaining a dynamic expansile root, it does not on its own address the annulus. Indeed, although by remodeling the root and pulling the commissures cephalad, this results in a correction of interleaflet triangle dilatation, this technique does not prevent future annular dilatation, especially in patients with severely dilated annuli or connective tissue disorders. A dilated annulus $(>25-28 \mathrm{~mm}$ ) has been shown to be a risk factor for recurrent $\mathrm{AI}$ and reoperation after the remodeling procedure alone for bicuspid or tricuspid valves $(2,3,26,27)$. This is not a problem with the reimplantation technique, which includes an annuloplasty through the proximal suture line of the tube (28). However, the reimplantation technique suffers with regards to hemodynamic effects showing loss of vortical flow, with risk of cusp impact on the tube graft and rapid valve closure (25).

Over time, both techniques have been modified to 
address their respective limitations. The remodeling technique has been improved by the addition of an external expansile annuloplasty ring in order to restore the normal annulus diameter in patients with a dilated annulus and prevent late dilatation of the annulus $(26,27,29-32)$. The reimplantation technique was adapted by using a spherical bulb-shaped graft to mimic the sinuses of Valsalva and improve vortical flow patterns and cusp motion $(33,34)$.

The reproducibility and long-term results of valvesparing root procedures have improved over the years. As well as addressing the annulus, this has been in part due to development of surgical techniques to address and repair the AV cusps. The systematic measurement of cusp eH has allowed the surgeon to assess for cusp prolapse, which may be pre-existing or induced as a result of the valve-sparing root procedure $(2,35)$. The durability of valve-sparing root procedures has been significantly improved by ensuring an intra-operative $\mathrm{eH}$ of at least $9 \mathrm{~mm}$ and good alignment of cusp free margin length (2).

Despite an annuloplasty being provided by both the reimplantation technique and the remodeling + ring technique, we prefer to use remodeling + ring based on a number of reasons. The first is related to superior haemodynamics in the remodeling technique with regards to vortical flow formation with preserved root expansibility and more physiological valve movements (25). Secondly, there are advantages to remodeling + ring with regards to the standardization and reproducibility of the technique. Whereas in the reimplantation technique the surgeon has to make a judgment on how high to place the commissures inside the graft, the commissures will follow the graft in the remodeling technique and will therefore be placed at the same level. Furthermore, as the annuloplasty is the first step carried out in the reimplantation technique through the proximal suture line, this means that subsequent $\mathrm{eH}$ measurement is hampered by having to measure within a small reduced annulus, making accurate measurements difficult. In contrast, the annuloplasty ring is the last step of the technique in remodeling + ring, therefore cusp eH is measured in an untouched (often large) annulus, making accurate measurement easier. Thirdly, the fallback option in aortic root repair if there is persistent AI after the crossclamp is removed is to re-clamp and replace the AV. In the case of reimplantation, this may mean inserting a prosthetic valve into a reduced small annulus, implying a small valve may be inserted. In remodeling + ring, the external ring could simply be cut and removed, thereby making the annulus enlarge again. This would provide space for inserting a large prosthetic ring. Despite this scenario being a relatively rare occurrence, it is of particular importance to new surgeons embarking on these techniques in their learning curve.

\section{Isolated AV repair-restoring the ratio STJ/ annulus}

Isolated $\mathrm{AI}$ is described when the sinuses of Valsalva and the ascending aorta are both $\leq 40-45 \mathrm{~mm}$. Despite the absence of significant aneurysmal disease, isolated dystrophic aortic AI presents almost constantly with an enlarged annulus and/or STJ, as part of the dystrophic spectrum of AI lesions (annulus $\geq 25 \mathrm{~mm}, \mathrm{STJ} \geq 30 \mathrm{~mm}$ ).

Aortic annuloplasty was first performed to treat isolated AI by Taylor and colleagues in 1958, the so called "aortic circumclusion", where silk sutures were placed as a circumferential annuloplasty running underneath the coronary arteries on a beating heart (36) (Figure 3). This operation quickly disappeared as the first AV replacement was carried out only 2 years later. Since then a number of different techniques of annuloplasty have been utilized, with different outcomes. The first internal annuloplasty technique was described by Cabrol et al. (38) in 1966, as part of addressing both the annulus and the STJ using sub- and supra-commissural plication sutures. The Cabrol subcommissural annuloplasty technique was adopted by many surgeons, with initial good outcomes reported by the Duran and Cosgrove groups $(39,40)$. However, with time, this technique has fallen out of favor due to the high rates of recurrent AI when the annulus is enlarged $(34,41)$. In bicuspid AVs, Aicher et al. showed that subcommissural annuloplasty was a predictor of re-operation when combined with remodeling root repair (42). de Kerchove et al. showed similar results in a bicuspid cohort, with $77 \%$ freedom from $\mathrm{AI} \geq 3$ at 4 years for subcommissural annuloplasty, compared to $100 \%$ for the reimplantation technique (34). A later comparison by the Brussels group showed subcommissural annuloplasty to be an independent predictor for $\mathrm{AV}$ re-operation due to redilatation of the aortic annulus in case of bicuspid but also for tricuspid valve (43).

A continuous $U$-shaped internal suture along the cusp insertion line was proposed by Carpentier (44), Haydar et al. (45), and Scholhorn et al. (46). This can be tied internally or externally with a Hegar dilator inside the annulus to aid in sizing the annuloplasty. Haydar et al. also reinforced the suture line with glutaraldehyde-soaked 
A

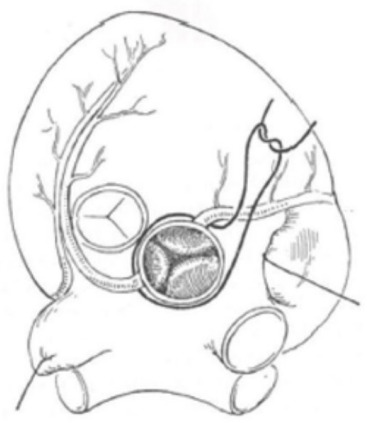

B

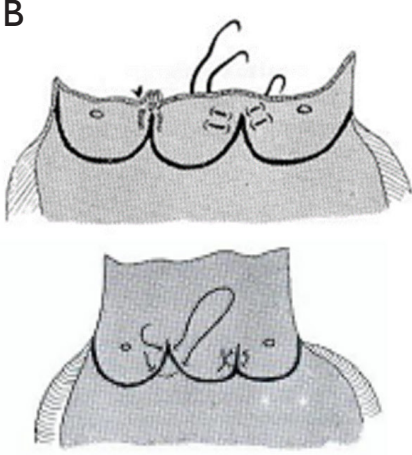

C

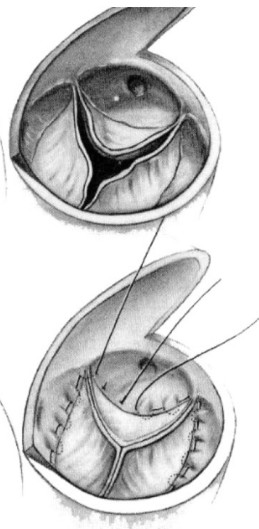

D

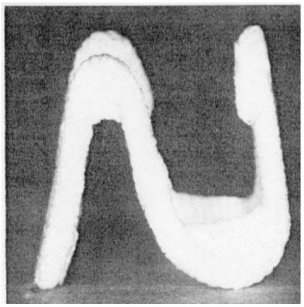

E

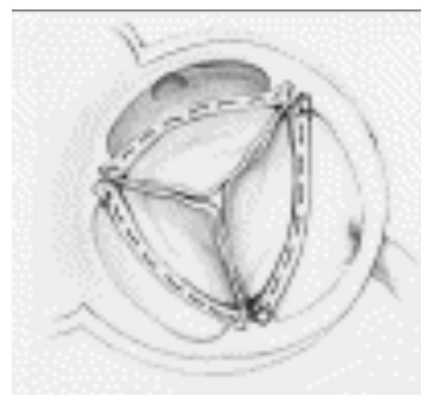

G

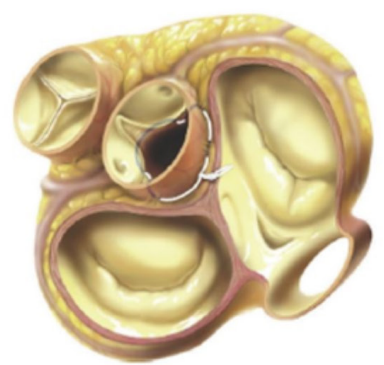

F

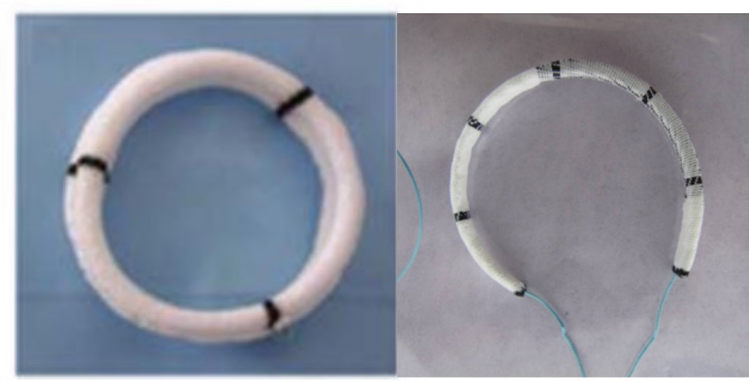

$\mathrm{H}$

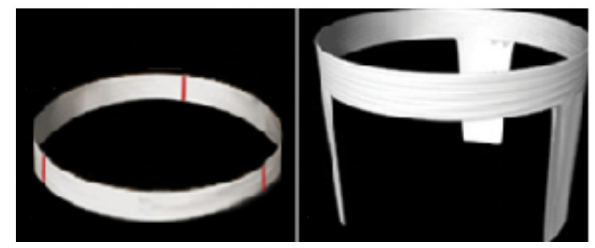

Figure 3 Different external annuloplasty techniques by Taylor 1958 (A), Cabrol 1966 (B), Carpentier 1983 (C), Duran 1993 (D), Haydar 1997 (E), Lansac 2003 (Coroneo, Inc. Extra-Aortic Ring) (F), Schafers 2009 (Suture Annuloplasty) (G), Fattouch 2011 (H), Rankin 2011 (HAART Ring) (I). Reprinted by permission from Springer Nature, Gen Thorac Cardiovasc Surg. Kunihara et al. (37).

pericardial strips (45). The results from these techniques remain unclear due to lack of available outcomes or very small patient numbers.

In 2003, Lansac et al. developed double sub- and supravalvular annuloplasty techniques using two external rings placed at the annulus and STJ levels for isolated AV repair $(26,27)$. Since the sinus of Valsalva are not dilated, the annuloplasty is performed with an open ring annuloplasty passed below the coronaries without detaching them in order to increase the surface of coaptation to protect the repair. Furthermore, the STJ must also be addressed in the form of a supravalvular annuloplasty. Whereas in valvesparing root procedures, the graft automatically provides a supravalvular STJ annuloplasty by bringing the commissure to the diameter of the tube, the STJ must be separately addressed in isolated AV repair. In order to achieve a good $\mathrm{cH}$ and long-term competency of the valve, the physiological ratios of the STJ/annulus diameter (i.e., 1.2) must be re-established as part of the repair process. Thus, a separate expansible annuloplasty at the supravalvular STJ level in addition to a subvalvular annuloplasty at the annular level using a standardised sizing system would 
provide both a reduction in respective diameters as well as maintaining the geometric ratio of STJ/annulus and systolic expansibility. In case of a dilated ascending aorta with preserved root, the subvalvular annuloplasty at STJ level will be performed by the supracoronary tube. In cases of borderline root diameters (close to $45 \mathrm{~mm}$ ), the decision to perform a valve-sparing root replacement would be indicated by the position of the coronary ostia being higher than the STJ (hence the STJ ring would be contra-indicated as it would cause coronary ischemia).

Fattouch et al. described a similar concept in 2011 with a home-made double annuloplasty (internal/external annuloplasty combined with a crown shaped ring for STJ annuloplasty) (47), showing midterm improvement in freedom from AI grade $\geq 2$ compared to subcommissural annuloplasty (48). Concerns remain regarding the interaction of the valve with an internal ring and potential left ventricular obstruction at subvalvular level.

In 2009, Schäfers et al. described circumferential suture annuloplasty using Ethibond and subsequently polytetrafluoroethylene Gore-Tex 0 suture, which improved outcomes compared to no annuloplasty, particularly for bicuspid valve repair $(3,49)$. Mid-term results from the Homburg group appear satisfactory but longer-term outcomes will determine the stability of this approach. This technique may be particularly useful in redo operations (e.g., when performing a valve-sparing root procedure in a dilated autograft root).

Following the work of Carlos Duran who first described an internal aortic ring in 1993 (implanted on only a small number of patients, subsequently abandoned with no clinical outcomes published), Schomburg and Rankin introduced in 2011 a rigid internal ring HAART (Hemispherical Aortic Annuloplasty Ring Technology) (50,51). To date, only early outcomes have been published on a limited number of patients (52). The issues which need to be assessed with long-term data include interaction of the valve with an internal rigid ring of pre-determined geometry and potential left ventricular obstruction of the subvalvular ring with incomplete STJ stabilization.

\section{Aortic annuloplasty: a standardised approach to AV repair}

As dystrophic AI almost constantly leads to dilatation of the annulus (>25 mm) and STJ (>30 mm), we have developed a standardised approach to AV repair which aims to restore the ratio between STJ/annulus. The procedure used is dependent on the phenotype of the aorta (Figure 1), but all procedures follow the same steps by performing: (I) alignment of cusp free margin length; then (II) supravalvular STJ annuloplasty; followed by (III) cusp eH assessment; and finally (IV) external ring subvalvular annuloplasty (if the annulus is $\geq 25 \mathrm{~mm}$ ). In the case of root aneurysms, the supravalvular STJ annuloplasty is performed by the remodeling root repair bringing the commissures to the diameter of the tube; with ascending aorta aneurysms, it is similarly performed by the supra coronary tube; in isolated AI, the supravalvular STJ annuloplasty is performed using an expansible aortic ring (Figure 1).

Since 2003, we have operated on 482 patients using this standardized approach with $92 \%$ freedom for reoperation at 8 years similar for bicuspid and tricuspid valves according to each phenotype of the proximal aorta. Furthermore, since 2007 we have used systematic eH assessment and expansible calibrated annuloplasty ring (Extra-Aortic; CORONEO, Inc., Montreal, QC, Canada) with the remodeling process, which has improved freedom from AI grade $\geq 3$ (100\%), re-operation $(99.1 \%)$ and major adverse valve-related events $(96.3 \%)$ at 7 years follow-up with similar results for bicuspid and tricuspid valve repair (53). Systolo-diastolic expansibility of the annulus was preserved following the annuloplasty $(5.1 \% \pm 9.5 \%)(54)$.

The safety of VSRR using the remodeling technique and expansible subvalvular annuloplasty has been demonstrated by the CAVIAAR trial showing similar 30-day mortality compared to a mechanical Bentall procedure, with a trend towards more major adverse events in the Bentall group (OR 2.52, $\mathrm{P}=0.09$ ) (55). At 4 years, crude and propensitymatched analyses confirmed that freedom from valverelated death and freedom from hemorrhagic events are significantly higher after valve repair than replacement; respectively $99 \%$ vs. $94 \%(\mathrm{P}<0.001)$ and $89 \%$ vs. $78 \%$ $(\mathrm{P}=0.02)$, whereas freedom from valve-related reoperation was similar $(\mathrm{P}=0.22)$.

More recently we looked at the impact of STJ stabilization on long-term durability of isolated AI repair, showing that use of double ring annuloplasty was associated with $100 \%$ freedom from recurrence of $\mathrm{AI} \geq$ Grade 3 compared to $67 \%$ in the single annuloplasty group at 6 years $(\mathrm{P}=0.008)$. Moreover, use of double annuloplasty was correlated with $97 \%$ freedom from $\mathrm{AV}$-related reintervention compared to $73 \%$ in the single annuloplasty group at 6 years $(\mathrm{P}=0.02)$. This technique showed results comparable to those of the valve-sparing procedures at 7 years (54). Long-term survival after AV repair is excellent and similar to sex- and age- 
matched populations.

\section{Conclusions}

Current medical evidence shows that AV repair is safe, reduces valve-related mortality compared to prosthetic valve replacement, produces better quality of life and provides a similar life expectancy to that of the general population. As was the case for mitral valve repair, dissemination of AV repair techniques will improve with standardization of a calibrated annuloplasty, thereby increasing the rate of $\mathrm{AV}$ repair for both tricuspid and bicuspid valves, even in patients with severe AI. Calibrated annuloplasty should be performed at sub- and supravalvular levels in order to restore the $\mathrm{STJ} / \mathrm{annulus}$ ratio and should be adapted according to the phenotype of the root and ascending aorta. Uniform clinical reporting of all available AV repair techniques, such as in the AVIATOR registry, will be key to evaluating long term patient outcomes (56).

\section{Acknowledgments}

P Youssefi was supported by the Royal College of Surgeons of England Research Fellowship, Dunhill Medical Trust Research Fellowship, and SCTS Ethicon Fellowship. The authors thank Pavel Zacek for his artistic contributions and assistance.

\section{Footnote}

Conflicts of Interest: E Lansac has consultant agreements with CORONEO, Inc. (www.coroneo.com), in connection with the development of an aortic ring bearing the trade name "Extra-Aortic". The other authors have no conflicts of interest to declare.

\section{References}

1. Falk V, Baumgartner H, Bax JJ, et al. 2017 ESC/EACTS Guidelines for the management of valvular heart disease. Eur J Cardiothorac Surg 2017;52:616-64.

2. Schafers HJ, Raddatz A, Schmied W, et al. Reexamining remodeling. J Thorac Cardiovasc Surg 2015;149:S30-6.

3. Schneider U, Aicher D, Miura Y, et al. Suture Annuloplasty in Aortic Valve Repair. Ann Thorac Surg 2016;101:783-5.

4. Iung B, Baron G, Butchart EG, et al. A prospective survey of patients with valvular heart disease in Europe: The
Euro Heart Survey on Valvular Heart Disease. Eur Heart J 2003;24:1231-43.

5. Detaint D, Jondeau G. Dystrophic aortic insufficiency. Rev Prat 2009;59:187-93.

6. Stamou SC, Williams ML, Gunn TM, et al. Aortic root surgery in the United States: A report from the Society of Thoracic Surgeons database. J Thorac Cardiovasc Surg 2015;149:116-22.e4.

7. Sievers HH, Hemmer W, Beyersdorf F, et al. The everyday used nomenclature of the aortic root components: the tower of Babel? Eur J Cardiothorac Surg 2012;41:478-82.

8. Anderson RH. Demolishing the tower of babel. Eur J Cardiothorac Surg 2012;41:483-4.

9. Frater RW, Anderson RH. How can we logically describe the components of the arterial valves? J Heart Valve Dis 2010;19:438-40.

10. Anderson RH, Devine WA, Ho SY, et al. The myth of the aortic annulus: the anatomy of the subaortic outflow tract. Ann Thorac Surg 1991;52:640-6.

11. Sutton JP 3rd, Ho SY, Anderson RH. The forgotten interleaflet triangles: a review of the surgical anatomy of the aortic valve. Ann Thorac Surg 1995;59:419-27.

12. de Kerchove L, El Khoury G. Anatomy and pathophysiology of the ventriculo-aortic junction: implication in aortic valve repair surgery. Ann Cardiothorac Surg 2013;2:57-64.

13. Lansac E, Di Centa I. Dynamic anatomy to aortic annuloplasty: the tale of the ring. In: Yankah CA, Weng YG, Hetzer R. editors. Aortic Root Surgery: The biological Solution. 1st edition. Berlin Heigdelberg: Springer-Verlag; 2010:102-32.

14. Bierbach BO, Aicher D, Issa OA, et al. Aortic root and cusp configuration determine aortic valve function. Eur J Cardiothorac Surg 2010;38:400-6.

15. Marom G, Haj-Ali R, Rosenfeld M, et al. Aortic root numeric model: annulus diameter prediction of effective height and coaptation in post-aortic valve repair. J Thorac Cardiovasc Surg 2013;145:406-11.e1.

16. Lansac E, Lim HS, Shomura Y, et al. A four-dimensional study of the aortic root dynamics. Eur J Cardiothorac Surg 2002;22:497-503.

17. de Kerchove L, Jashari R, Boodhwani M, et al. Surgical anatomy of the aortic root: implication for valve-sparing reimplantation and aortic valve annuloplasty. J Thorac Cardiovasc Surg 2015;149:425-33.

18. Khelil N, Sleilaty G, Palladino M, et al. Surgical anatomy of the aortic annulus: landmarks for external annuloplasty 
in aortic valve repair. Ann Thorac Surg 2015;99:1220-6.

19. Lansac E, de Kerchove L. Aortic valve repair techniques: state of the art. Eur J Cardiothorac Surg 2018;53:1101-7.

20. Anderson RH, Mori S. Nomenclature of the components of the aortic root. Eur J Cardiothorac Surg 2018. [Epub ahead of print].

21. Lansac E, de Kerchove L. Reply to Anderson and Mori. Eur J Cardiothorac Surg 2018. [Epub ahead of print].

22. Roman MJ, Devereux RB, Niles NW, et al. Aortic root dilatation as a cause of isolated, severe aortic regurgitation. Prevalence, clinical and echocardiographic patterns, and relation to left ventricular hypertrophy and function. Ann Intern Med 1987;106:800-7.

23. Sarsam MA, Yacoub M. Remodeling of the aortic valve anulus. J Thorac Cardiovasc Surg 1993;105:435-8.

24. David TE, Feindel CM. An aortic valve-sparing operation for patients with aortic incompetence and aneurysm of the ascending aorta. J Thorac Cardiovasc Surg 1992;103:61721; discussion 622.

25. Ranga A, Bouchot O, Mongrain R, et al. Computational simulations of the aortic valve validated by imaging data: evaluation of valve-sparing techniques. Interact Cardiovasc Thorac Surg 2006;5:373-8.

26. Lansac E, Di Centa I, Varnous S, et al. External aortic annuloplasty ring for valve-sparing procedures. Ann Thorac Surg 2005;79:356-8.

27. Lansac E, Di Centa I, Bonnet N, et al. Aortic prosthetic ring annuloplasty: a useful adjunct to a standardized aortic valve-sparing procedure? Eur J Cardiothorac Surg 2006;29:537-44.

28. de Kerchove L, Mastrobuoni S, Boodhwani M, et al. The role of annular dimension and annuloplasty in tricuspid aortic valve repair. Eur J Cardiothorac Surg 2016;49:42837; discussion 437-8.

29. Lansac E, Di Centa I, Raoux F, et al. Aortic annuloplasty: towards a standardized approach of conservative aortic valve surgery. Multimed Man Cardiothorac Surg 2007;2007:mmcts.2006.001958.

30. Lansac E, Di Centa I, Raoux F, et al. An expansible aortic ring for a physiological approach to conservative aortic valve surgery. J Thorac Cardiovasc Surg 2009;138:718-24.

31. Basmadjian L, Basmadjian AJ, Stevens LM, et al. Early results of extra-aortic annuloplasty ring implantation on aortic annular dimensions. J Thorac Cardiovasc Surg 2016;151:1280-5.e1.

32. Lenoir M, Maesen B, Stevens LM, et al. Reimplantation versus remodelling with ring annuloplasty: comparison of mid-term outcomes after valve-sparing aortic root replacement. Eur J Cardiothorac Surg 2018;54:48-54.

33. Oechtering TH, Hons CF, Sieren M, et al. Time-resolved 3-dimensional magnetic resonance phase contrast imaging (4D Flow MRI) analysis of hemodynamics in valve-sparing aortic root repair with an anatomically shaped sinus prosthesis. J Thorac Cardiovasc Surg 2016;152:418-27.e1.

34. de Kerchove L, Boodhwani M, Glineur D, et al. Valve sparing-root replacement with the reimplantation technique to increase the durability of bicuspid aortic valve repair. J Thorac Cardiovasc Surg 2011;142:1430-8.

35. Schafers HJ, Bierbach B, Aicher D. A new approach to the assessment of aortic cusp geometry. J Thorac Cardiovasc Surg 2006;132:436-8.

36. Taylor WJ, Thrower WB, Black H, et al. The surgical correction of aortic insufficiency by circumclusion. J Thorac Surg 1958;35:192-205 passim.

37. Kunihara T. Annular management during aortic valve repair: a systematic review. Gen Thorac Cardiovasc Surg 2016;64:63-71.

38. Cabrol C, Cabrol A, Guiraudon G, et al. Treatment of aortic insufficiency by means of aortic annuloplasty. Arch Mal Coeur Vaiss 1966;59:1305-12.

39. Duran CG. Reconstructive techniques for rheumatic aortic valve disease. J Card Surg 1988;3:23-8.

40. Cosgrove DM, Rosenkranz ER, Hendren WG, et al. Valvuloplasty for aortic insufficiency. J Thorac Cardiovasc Surg 1991;102:571-6; discussion 576-7.

41. le Polain de Waroux JB, Pouleur AC, Goffinet C, et al. Functional anatomy of aortic regurgitation: accuracy, prediction of surgical repairability, and outcome implications of transesophageal echocardiography. Circulation 2007;116:I264-9.

42. Aicher D, Kunihara T, Abou Issa O, et al. Valve configuration determines long-term results after repair of the bicuspid aortic valve. Circulation 2011;123:178-85.

43. Navarra E, El Khoury G, Glineur D, et al. Effect of annulus dimension and annuloplasty on bicuspid aortic valve repair. Eur J Cardiothorac Surg 2013;44:316-22; discussion 322-3.

44. Carpentier A. Cardiac valve surgery--the "French correction". J Thorac Cardiovasc Surg 1983;86:323-37.

45. Haydar HS, He GW, Hovaguimian H, et al. Valve repair for aortic insufficiency: surgical classification and techniques. Eur J Cardiothorac Surg 1997;11:258-65.

46. Schollhorn J, Rylski B, Beyersdorf F. Aortic valve annuloplasty: new single suture technique. Ann Thorac Surg 2014;97:2211-3.

47. Fattouch K, Sampognaro R, Speziale G, et al. New 
technique for aortic valve functional annulus reshaping using a handmade prosthetic ring. Ann Thorac Surg 2011;91:1154-8.

48. Fattouch K, Castrovinci S, Murana G, et al. Functional annulus remodelling using a prosthetic ring in tricuspid aortic valve repair: mid-term results. Interact Cardiovasc Thorac Surg 2014;18:49-54; discussion 54-5.

49. Schneider U, Hofmann C, Aicher D, et al. Suture Annuloplasty Significantly Improves the Durability of Bicuspid Aortic Valve Repair. Ann Thorac Surg 2017;103:504-10.

50. Schomburg JL, Lahti MT, Ruth GR, et al. Internal aortic annuloplasty: a novel technique. J Invest Surg 2011;24:222-6.

51. Rankin JS, Conger JL, Tuzun E, et al. In vivo testing of an intra-annular aortic valve annuloplasty ring in a chronic calf model. Eur J Cardiothorac Surg 2012;42:149-54.

52. Rankin JS, Mazzitelli D, Fischlein T, et al. Geometric Ring Annuloplasty for Aortic Valve Repair During Aortic

Cite this article as: Youssefi P, El-Hamamsy I, Lansac E. Rationale for aortic annuloplasty to standardise aortic valve repair. Ann Cardiothorac Surg 2019;8(3):322-330. doi: 10.21037/acs.2019.05.13
Aneurysm Surgery: Two-Year Clinical Trial Results. Innovations (Phila) 2018;13:248-53.

53. Lansac E, Di Centa I, Sleilaty G, et al. Remodeling root repair with an external aortic ring annuloplasty. J Thorac Cardiovasc Surg 2017;153:1033-42.

54. Lansac E, Di Centa I, Sleilaty G, et al. Long-term results of external aortic ring annuloplasty for aortic valve repair. Eur J Cardiothorac Surg 2016;50:350-60.

55. Lansac E, Bouchot O, Arnaud Crozat E, et al. Standardized approach to valve repair using an expansible aortic ring versus mechanical Bentall: early outcomes of the CAVIAAR multicentric prospective cohort study. J Thorac Cardiovasc Surg 2015;149:S37-45.

56. de Heer F, Kluin J, Elkhoury G, et al. AVIATOR: An open international registry to evaluate medical and surgical outcomes of aortic valve insufficiency and ascending aorta aneurysm. J Thorac Cardiovasc Surg 2018. [Epub ahead of print]. 